\title{
Rare Earth Elements (REE) analyses marking anthropogenic activities in archaeological strata
}

\author{
Gianni Gallello ${ }^{1}$
}

1 University of York

REE are a set of seventeen elements in the periodic table (fifteen lanthanides plus scandium and yttrium). A developed approach has proved that REE are able to distinguish between anthropogenic and non-anthropogenic sediments in archaeological strata. Furthermore, these chemical elements can help to determine the degree of human contribution to the formation of ancient soils ${ }^{[1][2]}$.

\section{References}

1. ^ Gianni Gallello, Agustin Pastor, Agustin Diez, Neus La Roca, Joan Bernabeu. (2013). Anthropogenic units fingerprinted by REE in archaeologicalstratigraphy: Mas d'Is (Spain) case. Journal of Archaeological Science, vol. 40 (2), 799-809.

2. ^Agustin Pastor, Gianni Gallello, M. Luisa Cervera, Miguel de la Guardia. (2016). Mineral soil composition interfacing archaeology and chemistry. TrAC Trends in Analytical Chemistry, vol. 78, 48-59. 